\title{
Adsorption Efficiency of a New Adsorbent Towards Uranium and Vanadium Ions at Low Concentrations
}

\author{
Pınar Akkaş Kavaklı, ${ }^{1}$ Noriaki Seko, ${ }^{2}$ Masao Tamada, ${ }^{2}$ \\ and Olgun Güven"* \\ ${ }^{1}$ Department of Chemistry, Hacettepe University, Beytepe, \\ Ankara, Turkey \\ ${ }^{2}$ Takasaki Radiation Chemistry Research Establishment, Japan \\ Atomic Energy Research Institute, Takasaki, Gunma, Japan
}

\begin{abstract}
A new type of fibrous adsorbent with excess amidoxime groups was synthesized by radiation-induced graft polymerization. Glycidyl methacrylate (GMA) was first radiation-grafted on polyethylene-coated polypropylene nonwoven fabrics and chemically modified with $3,3^{\prime}$ iminodipropionitrile [ $\left.\mathrm{NH}\left(-\mathrm{CH}_{2}-\mathrm{CH}_{2}-\mathrm{CN}\right)_{2}\right]$ (IDPN), which was further reacted with hydroxylamine to obtain graft chains containing two amidoxime groups per graft repeating units. The adsorption properties of this new adsorbent for uranium $(\mathrm{U})$, vanadium $(\mathrm{V})$, lead $(\mathrm{Pb})$, copper $(\mathrm{Cu})$, and cobalt $(\mathrm{Co})$ ions at low concentrations $(3.3-1000 \mathrm{ppb})$
\end{abstract}

*Correspondence: Olgun Güven, Department of Chemistry, Hacettepe University, Beytepe, 06532, Ankara, Turkey; E-mail: guven@ hacettepe.edu.tr.

1631

DOI: $10.1081 /$ SS-120030785

Copyright (C) 2004 by Marcel Dekker, Inc.
0149-6395 (Print); 1520-5754 (Online) www.dekker.com 
were investigated by a batch process. The adsorbent showed enhanced adsorption capacity for uranium and vanadium ions. In adsorption studies from a mixture of metal ions in aqueous solutions, the adsorbent showed selectivity for metal ions in the following order: $\mathrm{V}>\mathrm{U} \gg \mathrm{Cu} \geq \mathrm{Pb} \gg$ Co. The selectivity of the adsorbent was assessed by determining the distribution coefficient $D$, of the metal ions studied. The $\mathrm{U}$ and $\mathrm{V}$ ions were shown to be up to six times more selectively adsorbed onto the new adsorbent than the other metal ions.

Key Words: Radiation-induced grafting; Iminodipropionitrile modified GMA grafts; Uranium and vanadium ion selectivity; Adsorption efficiency.

\section{INTRODUCTION}

Uranium is one of the most valuable metals present in seawater. The concentration of uranium in seawater is remarkably constant at $3.3 \mathrm{mg} \mathrm{U} / \mathrm{m}^{3}$. Uranium exists in seawater mainly in the form of a tricarbonate complex, $\mathrm{UO}_{2}\left(\mathrm{CO}_{3}\right)_{3}^{4-\left[1{ }^{1,2]}\right.}$ Many types of adsorbents have been developed and tested for the recovery of uranium from seawater and aqueous media. ${ }^{[3-8]}$ Extensive investigations on adsorbents capable of recovering uranium from seawater and aqueous solutions have been carried out during the last two decades especially in the Takasaki Radiation Chemistry Research Establishment and the results were recently compiled in a nomogram by Saito and Sugo. ${ }^{[9]}$ In recent years, a wide range of chelating resins containing amidoxime groups were developed and evaluated for their ability to recover uranium from seawater and aqueous media. ${ }^{[10-12]}$ The chelating polymers include important properties such as high capacity, high selectivity, and fast kinetics. Egawa et al. prepared a number of macroreticular chelating resins containing amidoxime groups by reacting acrylonitrile-divinyl benzene copolymer beads with hydroxylamine. It was reported that these resins have high adsorption capacity for uranium in seawater. ${ }^{[3-5]}$ Sekiguchi et al. and Kawai et al. investigated the separative elution of uranium ions from an amidoxime polymer that had been immersed in seawater. ${ }^{[13,14]} \mathrm{A}$ number of papers published by Güven et al. investigated the preparation and properties of new copolymers with balanced hydrophilic and amidoxime group contributions for the uptake of uranyl ions from aqueous solutions. ${ }^{[15-18]}$ Kise et al. ${ }^{[19]}$ and Park et al. ${ }^{[20]}$ synthesized polystyrene-based chelating resins with a pair of amidoxime groups per repeating styrene units on polystyrene, in a geminate position, which could effectively coordinate to uranyl ions, by higher concentration of amidoxime groups. Accordingly, it was considered that the introduction of coordinating groups into a supporting polymer resin 
would enhance the adsorption rate and the selectivity for metal ion adsorption in aqueous media and, more specifically, uranyl ions in seawater. The synthesis of first acrylic bidentate amidoxime polymer was reported by amidoximation of a novel polymer, poly $\left(N, N^{\prime}\right.$-dipropionitrile acrylamide), as a new polymer with high affinity for uranyl ions. ${ }^{[21]}$ In an earlier work, we reported trying to prepare a novel adsorbent based on double amidoximation of iminodipropionitrile groups attached to glycidyl methacrylate (GMA) graft chains on a nonwoven fabric. ${ }^{[22]}$ In this work, the results of metal ion uptake studies from very dilute solutions using this novel adsorbent are reported.

\section{EXPERIMENTAL}

\section{Materials}

The adsorbent used in this work has recently been synthesized by radiation-induced graft polymerization technique. A nonwoven fabric made of polypropylene coated by polyethylene was used as the trunk polymer. The base polymer was irradiated by electron beams with a dose of $200 \mathrm{kGy}$ under $\mathrm{N}_{2}$ atmosphere and GMA was later grafted onto irradiated nonwoven fabric. Grafting conditions were optimized, and poly(glycidyl methacrylate) graft chains were modified with $3,3^{\prime}$-iminodipropionitrile (IDPN) in ethanol at $80^{\circ} \mathrm{C}$. Pendant nitrile groups introduced into the epoxy ring were then amidoximated by using hydroxylamine in methanol-water mixture. The relevant experimental details have already been reported elsewhere. ${ }^{[2]}$ The advantages of this new polymeric adsorbent containing two amidoxime groups per repeating unit of GMA side chains are the presence of excess amidoxime groups and an additional diethylene spacer unit between the neighboring amidoxime groups in each monomeric unit.

Standard solutions of $1000 \mathrm{ppm}$ for chemical analyses from Cica-reagent Kanto Chemical-Co Inc. were used for the adsorption studies of $\mathrm{V}, \mathrm{Pb}, \mathrm{Cu}$, and Co metal ions. In uranyl ion uptake studies, standard solution containing $10 \mathrm{ppm}$ of these metal ions were used by diluting them to required concentrations.

\section{Adsorption Experiments}

Amidoximated nonwoven fabric adsorbent was subjected to a pretreatment that involved contact for $2 \mathrm{hr}$ with a $2.5 \% \mathrm{KOH}$ solution at $80^{\circ} \mathrm{C}$. A known amount (around $0.025 \mathrm{~g}$ dry weight, $1 \times 1 \mathrm{~cm}^{2}$ ) of wet nonwoven fabric sample was then placed into metal ion solutions $(40 \mathrm{~mL})$. To obtain information on the relative performance of the amidoximated nonwoven 
adsorbent in kinetic terms, the adsorption of uranium, vanadium, lead, copper, and cobalt ions from $100 \mathrm{ppb}$ standard solutions at $\mathrm{pH} 5$ (acetate buffer solution) and $25^{\circ} \mathrm{C}$ were followed as a function of time, samples being taken for evaluation at $15,30,60$, and $120 \mathrm{~min}$ intervals. Once the adsorption equilibrium time was determined, the known weights of adsorbent samples were contacted with solutions containing different concentrations $(3.3,10,100$, 500 , and $1000 \mathrm{ppb}$ ) of metal ions at $\mathrm{pH} 5$ with continuous stirring at $25^{\circ} \mathrm{C}$ for those predetermined time periods.

Selective metal ion adsorption tests were performed by using a mixture of aqueous solution of 100 and $500 \mathrm{ppb}$ of each five metal ions by following the procedure given above. Metal ion concentrations after adsorption were determined by using a Hewlett Packard 4500 series Inductively Coupled Plasma (ICP) analyzer.

\section{RESULTS AND DISCUSSION}

Environmentally stable PE coated PP nonwoven fabric was used as the base material for the synthesis of a new adsorbent for metal ions. In order to introduce specific functional groups to the trunk polymer, GMA was first grafted onto preirradiated fabric. The resultant epoxy groups were opened and reacted with IDPN groups. The IDPN groups were introduced onto the graft chains of PE/PP nonwoven fabric at a conversion of $70 \%$, while maintaining the necessary physical strength of the fabrics. The nitrile groups were later converted to amidoxime groups, which are known to exhibit good affinity towards several metal ions, uranyl being the most selected. The reaction scheme is outlined in Sch. 1 and details related to the synthesis and characterization of this novel adsorbent have been given elsewhere. ${ }^{[22]}$

In order to investigate the adsorption kinetics of five different metal ions ( $\mathrm{U}, \mathrm{V}, \mathrm{Pb}, \mathrm{Cu}$, and $\mathrm{Co}$ ) onto new adsorbent, approximately $0.025 \mathrm{~g}$ of adsorbent was contacted with $100 \mathrm{ppb}$ metal ion solutions at $\mathrm{pH} 5$ buffer solution at $25^{\circ} \mathrm{C}$. Figure 1 shows the adsorption kinetics of $\mathrm{U}, \mathrm{V}, \mathrm{Cu}, \mathrm{Pb}$, and $\mathrm{Co}$ ions onto amidoximated nonwoven fabric. The ordinate values were given as the percentage of metal ions adsorbed from initial amounts.

High adsorption rates were observed within the first $20 \mathrm{~min}$ and the plateau values (i.e., adsorption equilibrium) were quickly reached at around $30 \mathrm{~min}$ for all metal ions investigated. Figure 1 shows that the new fabric adsorbent achieved almost $80 \%$ uranium and $92.5 \%$ vanadium loading in the first $30 \mathrm{~min}$ and almost complete removal of these two ions $99 \% \mathrm{U}(153.9 \mu \mathrm{g} / \mathrm{g})$ and $\mathrm{V}(150.1 \mu \mathrm{g} / \mathrm{g})$ within $2 \mathrm{hr}$. The adsorption equilibria for $\mathrm{Cu}, \mathrm{Co}$, and $\mathrm{Pb}$ ions were attained in about $30 \mathrm{~min}$, resulting with the adsorption of $72.7 \%$, 
Adsorption Efficiency of New Adsorbent Towards Metal Ions

169

170

171

172

173

174

175

176

177

178

179

180

181

182

183

184

185

186

187

188

189

190

191

192

193

194

195

196

197

198

199

200

201

202

203

204

205

206

207

208

209

210
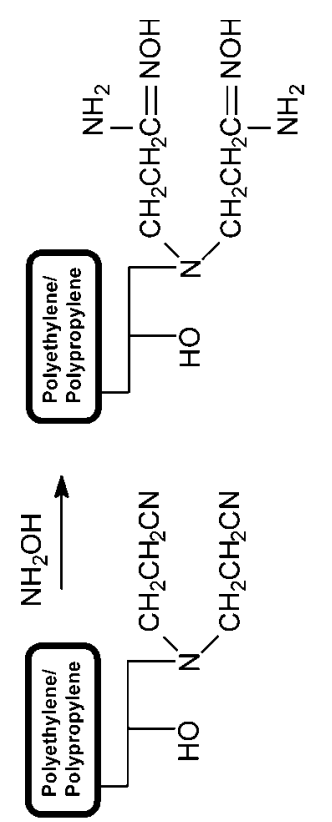

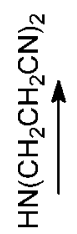
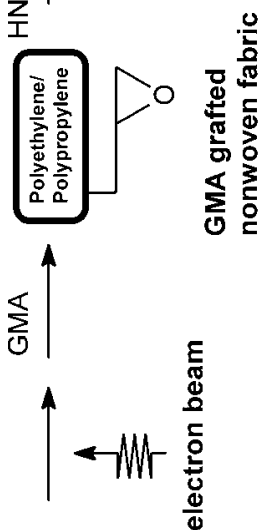

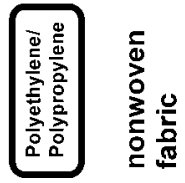

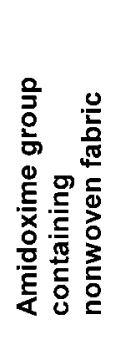

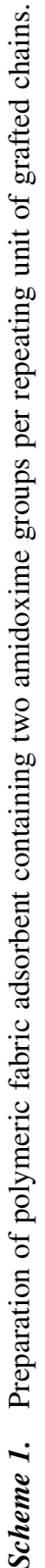




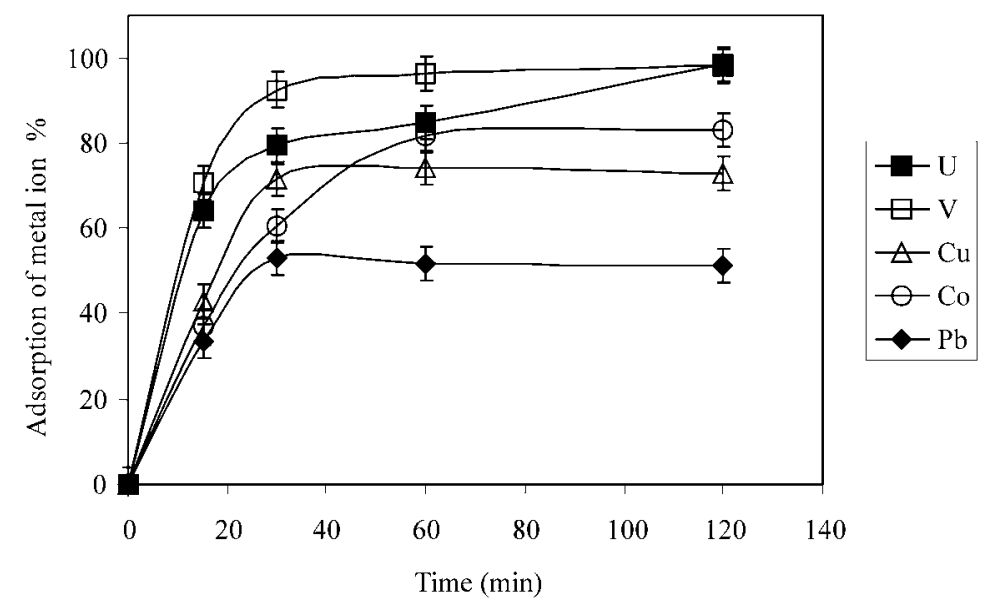

Figure 1. Adsorption kinetics of various metal ions from the same initial concentrations.

$83 \%$, and $51.4 \%$ of $\mathrm{Cu}, \mathrm{Co}$, and $\mathrm{Pb}$ ions, respectively, which correspond to equilibrium removal amounts of $134.9,112.3,56.2 \mu \mathrm{g} / \mathrm{g}$, respectively.

The effect of initial concentration of metal ions on the adsorption behavior of amidoximated nonwoven fabric was determined for five different metal ion concentrations $(3.3,50,100,500$, and $1000 \mathrm{ppb})$, and the results are given

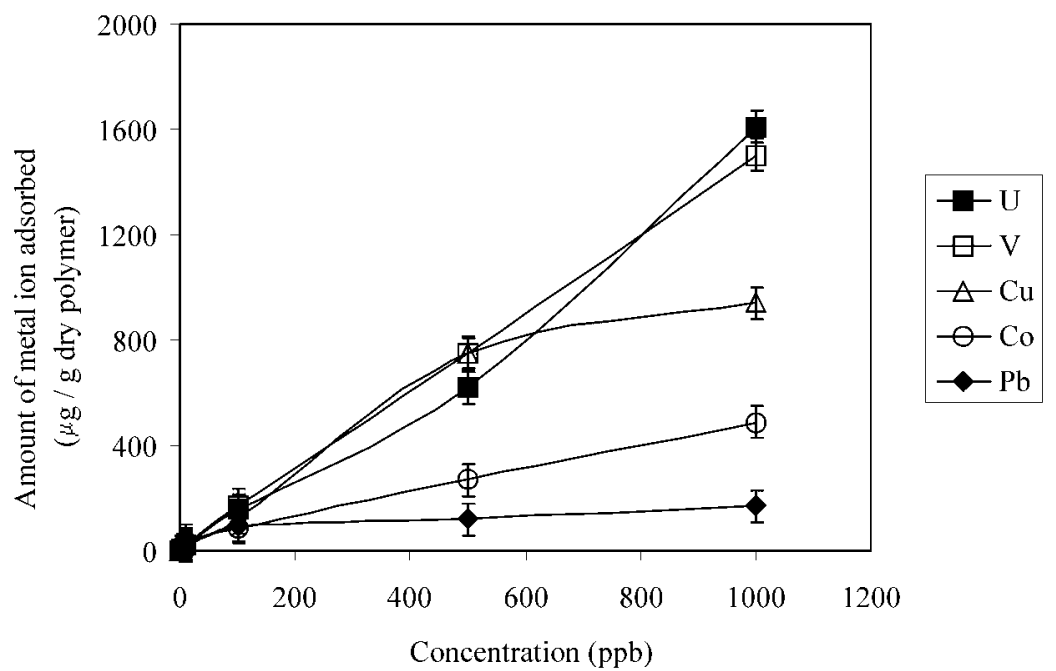

Figure 2. Dependence of metal ion uptake on the initial concentrations of metal ions. 
collectively in Fig. 2. Figure 2 shows that the adsorption of metal ions increased almost linearly with an increase in the initial metal ion concentration. The new adsorbent exhibited a higher affinity for $\mathrm{U}$ and $\mathrm{V}$ ions, the highest values were found to be 1610 and $1501 \mu \mathrm{g} / \mathrm{g}$ from $1000 \mathrm{ppb}$ metal ion solution, respectively. One hundred percent adsorption of uranium and vanadium ions was reached easily for all concentrations studied. The quantitative removal of other ions were found to be 940,489 , and $168 \mu \mathrm{g} / \mathrm{g}$ for $\mathrm{Cu}, \mathrm{Co}$, and $\mathrm{Pb}$ ions, respectively, from solutions containing $1000 \mathrm{ppb}$ metal ions. The percentage amount of $\mathrm{Co}$, $\mathrm{Pb}$, and $\mathrm{Cu}$ ions adsorbed by the fabric initially increased with the increasing concentration of $\mathrm{Cu}$ ion up to $500 \mathrm{ppb}(93.5 \%)$ and $\mathrm{Pb}$ ion up to $100 \mathrm{ppb}$ $(83.9 \%)$. At higher initial concentrations of these metal ions, their adsorptivities were not affected and even at the highest concentration of $1000 \mathrm{ppb}$, the values corresponding to 100 and $500 \mathrm{ppb}$ concentrations were not appreciably exceeded. This can be explained by the initial saturation of active sites available for $\mathrm{Cu}$ and $\mathrm{Pb}$ ions on the amidoximated nonwoven fabric. Adsorption of $\mathrm{Co}$ ions presents an interesting case where maximum adsorption of $65.2 \%$ was observed at the lowest concentration of $3.3 \mathrm{ppb}$. Lesser adsorption was obtained upon further increase in initial concentration.

The adsorption capacity for uranyl ions by the adsorbent prepared in this work was found to be better than that of the chelating resins prepared by the method of Park et al. and Kise et al. ${ }^{[19,20]}$ The advantages of this new polymeric adsorbent containing two amidoxime groups per repeating unit of GMA side chains are the presence of excess amidoxime groups and an additional diethylene spacer unit between the neighboring amidoxime groups in each monomeric unit. It can be said that this adsorbent is the first grafted nonwoven fabric reported in the literature possessing bidentate amidoxime groups. These properties make this new adsorbent more accessible and efficient for the adsorption of metal ions in aqueous systems compared to conventional adsorbents having only one amidoxime group as the pendant group of the repeating units. It also shows good stability along with faster rate of equilibrium for all the metal ions studied here.

The selectivity of this new adsorbent against certain metal ions was also checked. Figure 3 shows selective behavior of the adsorbent for $\mathrm{U}$ and $\mathrm{V}$ ions. The selectivity is expressed in terms of the distribution coefficient (D), which has been frequently used as a measure of capacity of an adsorbent. ${ }^{[23]}$

$$
D=\frac{\mathrm{mg} \mathrm{M}^{n+} / \mathrm{g} \text { of dry polymer adsorbent }}{\mathrm{mg} \mathrm{M}^{n+} \mathrm{mL} \text { of solution }}
$$

The distribution coefficients of each metal ion were determined under competitive conditions by using the equation given above. 


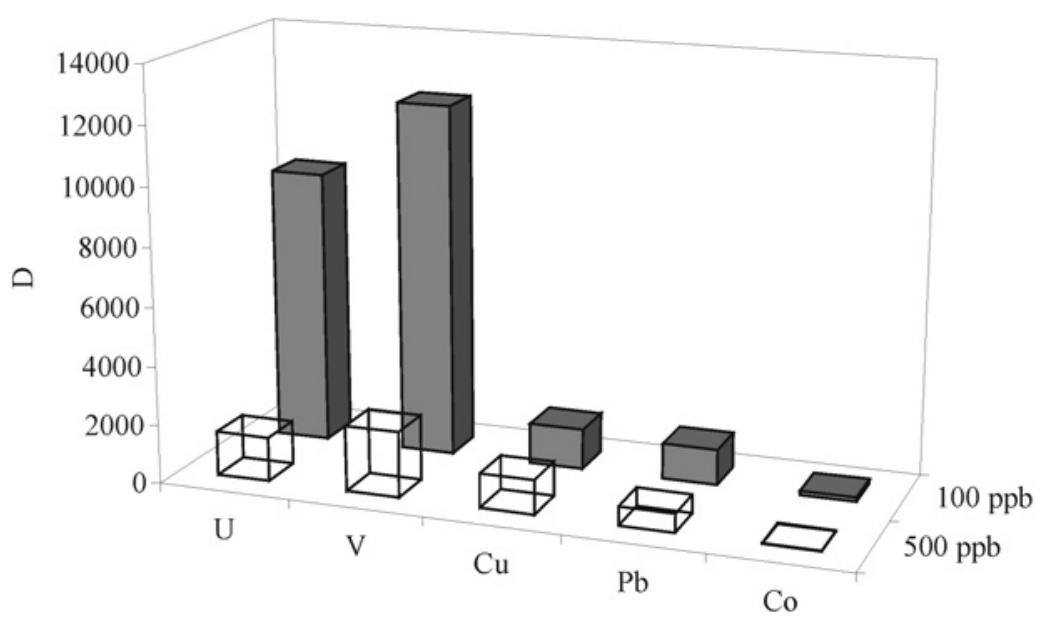

Figure 3. Adsorption selectivity of amidoximated nonwoven fabric for the indicated metal ions at two different initial concentrations.

For the concentration range studied here, adsorption of $\mathrm{U}$ and $\mathrm{V}$ ions have been found to be higher than those of $\mathrm{Cu}, \mathrm{Pb}$, and $\mathrm{Co}$. The order of decreasing selectivity is $\mathrm{V}>\mathrm{U} \gg \mathrm{Cu} \geq \mathrm{Pb} \gg \mathrm{Co}$ for 100 and $500 \mathrm{ppb}$ solutions of metal ion mixtures. This selectivity order is in good accordance with the decreasing order of ionic radii of these metal ions in aqueous solution. ${ }^{\text {[24] }}$ The distribution coefficients calculated for $\mathrm{U}$ and $\mathrm{V}$ ions showed that their adsorption from $100 \mathrm{ppb}$ mixture solution is up to six times higher than adsorption from a $500 \mathrm{ppb}$ mixture solution. The lower the concentration of metal ions remaining in solution the higher become the $D$ values. This general behavior is associated with the definition of $D$ values. The lower the initial metal ion concentration of a solution, the smaller the concentration of ions remaining in the solution gets. This makes the denominator smaller and $D$ values, in turn, higher. In both concentrations studied here 100 and $500 \mathrm{ppb}$, however, the selectivity of adsorbent towards $\mathrm{U}$ and $\mathrm{V}$ ions was found to be significantly higher than for the other ions. These results show that the new adsorbent is quite efficient for the uptake of trace amounts of $\mathrm{U}$ and $\mathrm{V}$ ions from seawater or other aqueous media. This selectivity follows the same order as that found for another amidoxime-containing adsorbent. ${ }^{\text {[20] }}$

There have been numerous attempts in developing speciality adsorbents for the uptake of uranyl ions from aqueous solutions and seawater. A comparative evaluation was made to see the uranyl ion adsorption capacity of various adsorbents developed by different groups and the new adsorbent developed by our group. Adsorbent systems listed in Table 1 include only those based on 
Adsorption Efficiency of New Adsorbent Towards Metal Ions

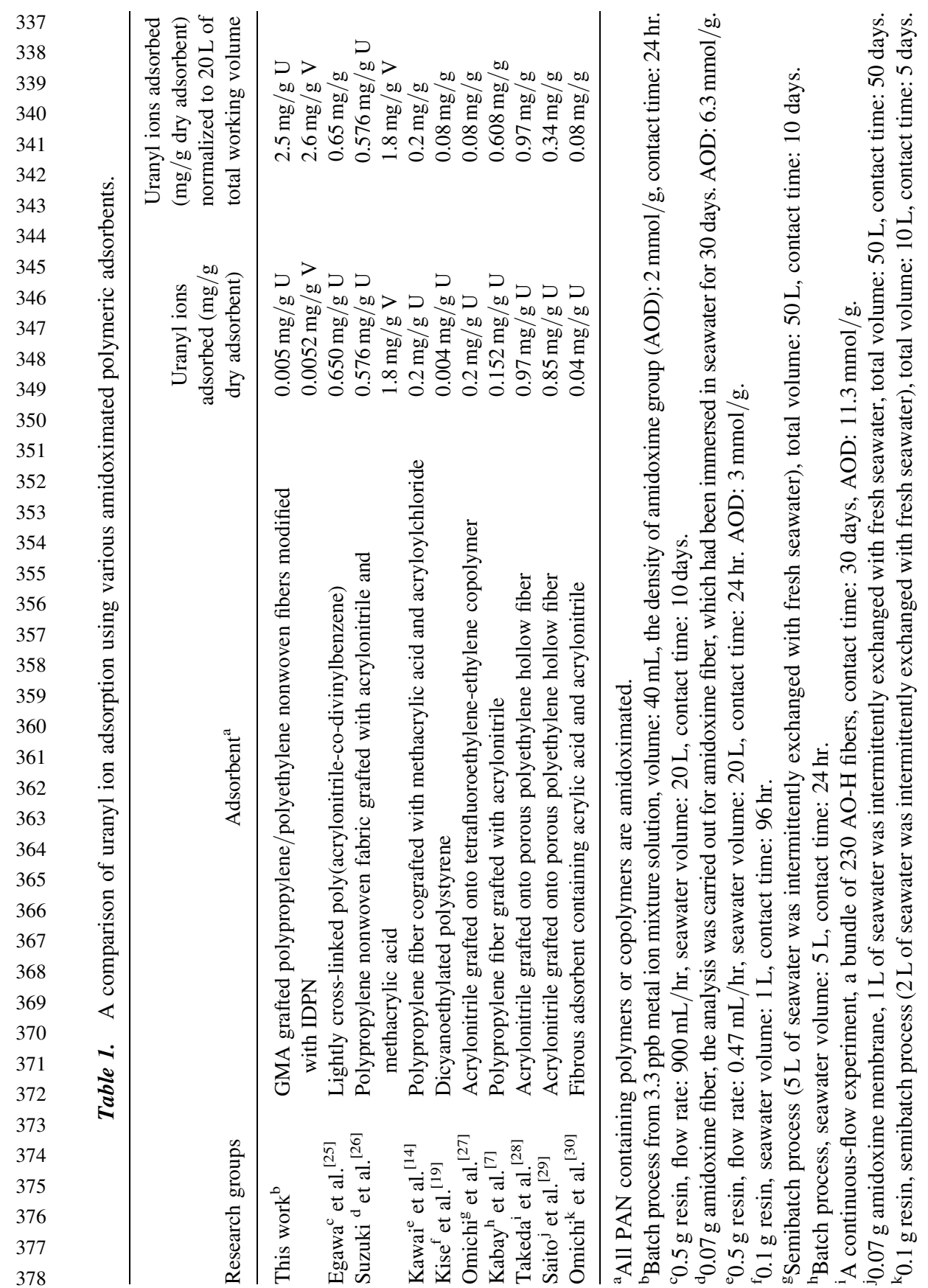


amidoximated polyacrylonitrile polymers and copolymers. The volumes of uranyl ion containing solutions in these batch, semi-batch, and continuous systems ranged from $40 \mathrm{~mL}$ to $50 \mathrm{~L}$, the most frequently used volume is $20 \mathrm{~L}$ to which all other volumes are normalized. This approach, although not comprising all factors affecting the efficiency of an adsorbent (surface area, shape, contact mode, etc.) seemed to be an easy and simple way of comparing adsorption capacities of systems investigated. When the efficiencies corresponding to adsorption values are normalized to $20 \mathrm{~L}$, and working solutions are compared as given in the far right column of Table 1 , one can see that they can be grouped under three categories: low efficiency $(0.08-0.20 \mathrm{mg} / \mathrm{g})$, medium efficiency $(0.34-0.65 \mathrm{mg} / \mathrm{g})$, and high efficiency $(0.97-2.50 \mathrm{mg} / \mathrm{g})$ adsorbents. Although this list is not exhaustive, the highest uranyl ion adsorption efficiency was obtained with the new adsorbent developed in this work. In some of the studies cited in Table 1, together with uranyl ions, the uptake of vanadyl ions was also determined. High efficiency of the new adsorbent is also seen for vanadyl ions. Further details related to adsorbent properties and adsorption conditions are given in Table 1.

\section{CONCLUSION}

A new fibrous adsorbent containing two adjacent amidoxime groups in graft chain repeating units has been shown to provide a rapid uptake within 30 min for the metal ions, $\mathrm{U}, \mathrm{V}, \mathrm{Cu}, \mathrm{Pb}, \mathrm{Co}$, studied here with high capacity for $\mathrm{U}$ and $\mathrm{V}$ ions. Adsorption of $100 \%$ of uranium and vanadium ions for all concentrations studied $(3.3-1000 \mathrm{ppb})$ were achieved. When adsorption was studied from a mixture of ions mentioned above, quite high selectivity was observed for $\mathrm{U}$ and $\mathrm{V}$ ions adsorption in the presence of other ions. The order of selectivity determined by calculating the distribution coefficient, $D$, of metal ions was found to be in the order of $\mathrm{V}>\mathrm{U} \gg \mathrm{Cu} \geq \mathrm{Pb} \gg \mathrm{Co}$. Uptake of $2.5 \mathrm{mg}$ metal ion $/ \mathrm{g}$ of adsorbent has been achieved both for uranium and vanadium ions from aqueous solutions with concentrations similar to seawater concentrations, $3.3 \mathrm{ppb}$. Further work is in progress in using actual seawater in adsorption experiments as well as cyclic use of the fabric, and its efficiency on repeated use.

\section{ACKNOWLEDGMENTS}

One of the authors (P.A.K.) thanks IAEA (Grant No: TUR8016) for the fellowship provided to carry out part of this work at the Takasaki Radiation Chemistry Research Establishment of JAERI. The authors are also grateful 
to Haruyo Amada and Fatmuanis Basuki for their help with some of the experiments.

Continuous interest and support by Takanobu SUGO are greatly appreciated.

\section{REFERENCES}

1. Saito, K.; Miyauchi, T. Diffusivities of uranium in artificial seawater. Kagaku Kogagu Ronbun 1981, 7, 545-548.

2. Saito, K.; Miyauchi, T. Chemical forms of uranium in artificial seawater. J. Nucl. Sci. Technol. 1982, 19, 145-150.

3. Egawa, H.; Harada, H. Recovery of uranium from seawater by using chelating resins containing amidoxime groups. Nippon Kagaku Kaishi 1979, 958-959.

4. Egawa, H.; Harada, H.; Nonaka, T. Preparation of adsorption resins for uranium in seawater. Nippon Kagaku Kaishi 1980, 1767-1772.

5. Egawa, H.; Harada, H.; Shuto, T. Recovery of uranium from seawater by the use of chelating resins containing amidoxime groups. Nippon Kagaku Kaishi 1980, 1773-1776.

6. Astheimer, L.; Schenk, H.J.; Witte, E.G.; Schwachau, K. Development of sorbers for the recovery of uranium from seawater. Part 2 . The accumulation of uranium from seawater by resins containing amidoxime, imidoxime functional groups. Sep. Sci. Technol. 1983, 18, 307-339.

7. Kabay, N.; Katakai, A.; Sugo, T.; Egawa, H. Preparation of fibrous adsorbents containing amidoxime groups by radiation-induced grafting and application to uranium recovery from seawater. J. Apply. Polym. Sci. 1993, 49, 599-607.

8. Akkaş, P.; Güven, O. Enhancement of uranyl ion uptake by prestructuring of acrylamide-maleic acid hydrogels. J. Appl. Polym. Sci. 2000, 78, 284-289.

9. Saito, K.; Sugo, T. Mission: possible radiation-induced graft polymerization [1983-2000], private communication. 2000.

10. Schenk, H.J.; Asthemier, L.; Witte, E.G.; Schwochau, K. Development of sorbers for the recovery of uranium from seawater. 1. Assessment of key parameters and screening studies of sorber materials. Sep. Sci. Technol. 1982, 17, 1293-1308.

11. Rivas, B.L.; Seguei, G.V.; Geckeler, K.E. Synthesis, characterization, and properties of polychelates of poly(styrene sulfonic acid-co-maleic acid) with $\mathrm{Co}(\mathrm{II}), \mathrm{Cu}(\mathrm{II}), \mathrm{Ni}(\mathrm{II})$, and $\mathrm{Zn}(\mathrm{II})$. J. Appl. Polym. Sci. 2002, 85, 2546-2551. 
12. Rivas, B.L.; Pooley, S.A.; Maturana, H.A.; Villegas, S. Metal ion uptake properties of acrylamide derivative resins. Macromol. Chem. Phys. 2001, 202, 443-447.

13. Sekiguchi, K.; Saito, K.; Konishi, S.; Furusaki, S.; Sugo, T.; Nabukawa, H. Effect of seawater temperature on uranium recovery from seawater using amidoxime adsorbents. Ind. Eng. Chem. Res. 1994, 33, 662-666.

14. Kawai, T.; Saito, K.; Sugita, K.; Kawakami, T.; Kanno, J.; Katakai, A.; Seko, N.; Sugo, T. Preparation of hydrophilic amidoxime fibers by cografting acryonitrile and methacrylic acid from an optimized monomer composition. Rad. Phys. Chem. 2000, 59, 405-411.

15. Şahiner, N.; Pekel, N.; Güven, O. Radiation synthesis of $N$-vinyl 2-pyrrolidone/acrylonitrile interpenetrating polymer networks and their use in uranium recovery from aqueous systems. Rad. Phys. Chem. 1998, 52, 271-276.

16. Şahiner, N.; Pekel, N.; Güven, O. Radiation synthesis, characterization and amidoximation of $\mathrm{N}$-vinyl-2-pyrrolidone/acrylonitrile interpenetrating polymer networks. React. Funct. Polym. 1999, 39, 139-146.

17. Şahiner, N.; Pekel, N.; Akkaş, P.; Güven, O. Amidoximation and characterization of new complexing hydrogels prepared from $N$-vinyl 2-pyrrolidone/ acrylonitrile systems. J.M.S.-Pure Appl. Chem. 2000, A37, 1159-1172.

18. Pekel, N.; Şahiner, N.; Akkaş, P.; Güven, O. Uranyl ion adsorptivity of $\mathrm{N}$-vinyl 2-pyrrolidone/acrylonitrile copolymeric hydrogels containing amidoxime group. Polym. Bull. 2000, 44, 593-600.

19. Kise, H.; Sato, H. Synthesis of a new chelate resin for uranium adsorption from seawater. Polystyrene resin containing two amidoxime functions in the repeating unit. Makromol. Chem. 1985, 186, 2449-2454.

20. Park, I.H.; Suh, J.M. Preparation and uranyl ion adsorptivity of macroreticular chelating resins containing a pair of neighboring amidoxime groups in a monomeric styrene unit. Angew. Makromol. Chem. 1996, 239, 121-132.

21. Kavaklı Akkaş, P.; Uzun, C.; Güven, O. Synthesis, characterization and amidoximation of a novel polymer: poly $\left(N, N^{\prime}\right.$-dipropionitrile acrylamide $)$. React. Funct. Polym. 2004, in press.

22. Kavaklı Akkaş, P.; Seko, N.; Tamada, M.; Güven, O. to be published.

23. Rodrigues, A.E. Ion Exchange Sci. Technol., NATO ASI series/E; 1986; Vol. 107, 35.

24. Huheey, J.M. Inorganic Chemistry: Principles of Structure and Reactivity, 3rd Ed.; Harper Collins Publishers, Inc.: New York, 1983; 73.

25. Egawa, H.; Kabay, N.; Saigo, S.; Nonaka, T.; Shuto, T. Low-crosslinked porous chelating resins containing amidoxime groups. Bull. Soc. Sea Water Sci. Jpn. 1991, 45, 324-332. 
26. Suzuki, T.; Saito, K.; Sugo, T.; Ogura, H.; Oguma, K. Analy. Sci., fractional elution and determination of uranium and vanadium adsorbed on amidoxime fiber from seawater. The Jpn. Soc. Analy. Chem. 2000, 16, 429-432.

27. Omichi, H.; Katakai, A.; Sugo, T.; Okamoto, J. A new type of amidoximegroup-containing adsorbent for recovery of uranium from seawater. III. Recycle use of adsorbent. Sep. Sci. Technol. 1986, 21, 563-574.

28. Takeda, T.; Saito, K.; Uezu, K.; Furusaki, S.; Sugo, T.; Okamoto, J. Adsorption and elution in hollow-fiber-packed bed for recovery of uranium from seawater. Ind. Eng. Chem. Res. 1991, 30, 185-190.

29. Saito, K.; Yamaguchi, T.; Uezu, K.; Frusaki, S.; Sugo, T.; Okamoto, J. Optimum preparation conditions of amidoxime hollow fiber synthesized by radiation-induced grafting. J. Appl. Polym. Sci. 1990, 39, 2153-2163.

30. Omichi, H.; Katakai, A.; Sugo, T.; Okamoto, J. A new type of amidoximegroup-containing adsorbent for the recovery of uranium from seawater. Sep. Sci. Technol. 1985, 20, 163-178.

Received May 2003

Accepted November 2003 


\begin{tabular}{|c|c|c|}
\hline \multirow{19}{*}{ 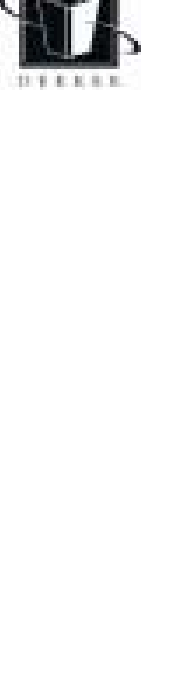 } & CMS ID number (DOI): & 120030785 \\
\hline & Article title: & $\begin{array}{l}\text { Adsorption Efficiency of a New Adsorbent Towards Uranium and Vanadium lons at Low } \\
\text { Concentrations }\end{array}$ \\
\hline & Article type: & Research \\
\hline & Classification: Category: & \\
\hline & Primary subcategory: & \\
\hline & Subcategpry(ies): & \\
\hline & Topic(s): & \\
\hline & Key words: & $\begin{array}{l}\text { Radiation-induced grafting; Iminodipropionitrile modified GMA grafts; Uranium and vanadium ion } \\
\text { selectivity; Adsorption efficiency }\end{array}$ \\
\hline & Copyright holder: & \\
\hline & Author Sequence Number & 4 \\
\hline & Author first name or first initial: & Olgun \\
\hline & Author middle initial: & \\
\hline & Author last name: & Güven \\
\hline & Suffix to last name: & \\
\hline & Degrees: & \\
\hline & Author Status & \\
\hline & Author e-mail address: & guven@hacettepe.edu.tr \\
\hline & Author fax: & \\
\hline & Author phone: & \\
\hline \multirow{10}{*}{$\begin{array}{l}\text { Primary } \\
\text { Affiliation(s) at } \\
\text { time of } \\
\text { authorship: }\end{array}$} & Title or Position & \\
\hline & Department(s) & Department of Chemistry \\
\hline & Institution or Company & Hacettepe University \\
\hline & Domestic (U.S.A.) or International & International \\
\hline & Suite, floor, room no. & \\
\hline & Street address & \\
\hline & City & Beytepe \\
\hline & State/Province & Ankara \\
\hline & Postal code & 06532 \\
\hline & Country & Turkey \\
\hline \multirow{10}{*}{$\begin{array}{l}\text { Secondary } \\
\text { Affiliation(s) at } \\
\text { time of } \\
\text { authorship: }\end{array}$} & Title or Position & \\
\hline & Department(s) & \\
\hline & Institution or Company & \\
\hline & Domestic (U.S.A.) or International & \\
\hline & Suite, floor, room no. & \\
\hline & Street address & \\
\hline & City & \\
\hline & State/Province & \\
\hline & Postal code & \\
\hline & Country & \\
\hline \multirow{9}{*}{$\begin{array}{l}\text { Current } \\
\text { affiliation(s): }\end{array}$} & Title or Position & \\
\hline & Department(s) & \\
\hline & Institution or Company & \\
\hline & Suite, floor, room no. & \\
\hline & Street address & \\
\hline & City & \\
\hline & State/Province & \\
\hline & Postal code & \\
\hline & Country & \\
\hline \multirow{8}{*}{ Mailing address: } & Department(s) & \\
\hline & Institution or Company & \\
\hline & \begin{tabular}{|l|} 
Street address \\
\end{tabular} & \\
\hline & Suite, floor, room no. & \\
\hline & City & \\
\hline & State/Province & \\
\hline & $\begin{array}{l}\text { Postal code } \\
\end{array}$ & \\
\hline & Country & \\
\hline \multirow{3}{*}{$\begin{array}{l}\text { Recipient of R1 } \\
\text { proofs: }\end{array}$} & e-mail address to receive proofs: & guven@hacettepe.edu.tr \\
\hline & Fax to receive proofs: & \\
\hline & Mailing address to receive proofs: & \\
\hline \multirow[t]{4}{*}{ Article data: } & Submission date: & \\
\hline & Reviewed date: & May-03 \\
\hline & Revision date: & \\
\hline & Accepted date: & Nov-03 \\
\hline
\end{tabular}

